\title{
1. EL TRATADO DE UNIFICACIÓN ENTRE LA REPÚBLICA FEDERAL DE ALEMANIA Y LA REPÚBLICA DEMOCRÁTICA ALEMANA COMO BASE DE LA UNIFICACIÓN ALEMANA DEL 3 DE OCTUBRE DE 1990
}

\author{
RAINER ARNOLD \\ Catedrático de Derecho Público \\ Universidad de Regensburg (RFA)
}




\section{SUMARIO}

1. IntRoducción.-2. Breve Relación cronológica del desarrollo de los acontecimientos.-3. Naturaleza juRídica del TU.-4. RÉgimen ESPECIAL DEL DERECHO DE PROPIEDAD.-5. LA CREACIÓN DE NUEVOS ESTADOS Federados.-6. Recepción del derecho federal en los nueVos Estados Federales.-7. Otras consecuencias Jurídicas de la unificación aleMANA. 
Revista de Derecho Político, núm. 40, 1995, pp. 11-28

\title{
1. EL TRATADO DE UNIFICACIÓN ENTRE LA REPÚBLICA FEDERAL DE ALEMANIA Y LA REPÚBLICA DEMOCRÁTICA ALEMANA COMO BASE DE LA UNIFICACIÓN ALEMANA DEL 3 DE OCTUBRE DE $1990^{1}$
}

POR

\author{
RAINER ARNOLD \\ Catedrático de Derecho Público \\ Universidad de Regensburg (RFA)
}

\section{INTRODUCCIÓN}

El Tratado de Unificación (en adelante, TU) entre las dos partes de Alemania es el instrumento jurídico de mayor relevancia entre los que han posibilitado la unificación realizada el pasado 3 de octubre de 1990, siendo válido, desde este momento también, como derecho federal, en parte de naturaleza ordinaria (en su mayoría) y en parte constitucional ${ }^{2}$, y supone el marco de la relación entre los nuevos y los Estados Federados existentes hasta aquel momento.

EI TU, que ha originado una amplia reforma de la Ley Fundamental (suponiendo la modificación del Preámbulo y de los artículos 146, 51.2 y 135.a, la supresión del artículo 23 y la creación del artículo 143, así como determinadas recomendaciones para posteriores reformas constitucionales), contiene las directrices fundamentales que configurarán el de-

- La redacción en español del presente artículo ha sido realizada con la colaboración de Francisco Javier CREMADES GaRCía, "Wissenchaftliche Hilfskraft" en la Cátedra de Derecho Público de la Universidad de Ratisbona (RFA) y Becario de Investigación de la UNED.

2 Cfr. artículo 45.2 del Tratado de Unificación (TU). BGBI, II, 1990, 889. 
sarrollo del ordenamiento jurídico de la Alemania unida. Los principios básicos del TU, recogidos en su Preámbulo junto a una llamada a la continuidad de la historia alemana (completándola consecuentemente con la unidad nacional, a través de un acto de autodeterminación libre) y a su responsabilidad particular resultante del pasado, sobre un desarrollo democrático en Alemania (supeditado, también en el futuro, a la protección de la paz y los derechos humanos), tienen una validez reconocida tanto por el derecho interno (Estado de derecho, democracia, federalismo y Estado social), como por el derecho Internacional (promoción de la paz en el convencimiento de la inviolabilidad de las fronteras y de la integridad territorial y soberanía de todos los Estados en Europa; contribución, a través de la unidad alemana, a la integración de Europa, así como a la instauración de un orden de paz europeo). Esto implica, entre otras cosas, la existencia de disposiciones significativas de adaptación con respecto a la siguiente problemática:

a) Validez del derecho de la RFA en el territorio de la antigua RDA.

b) Recepción, en determinados casos, del derecho de la RDA.

c) Necesidad de ciertas modificaciones de la Ley Fundamental de Bonn.

d) Dispensas necesarias durante un determinado período de tiempo, respecto a la constitucionalidad de algunas disposiciones normativas transitorias.

e) Continuidad de los Tratados Internacionales concluidos válidamente por la RDA y en particular la solución de los problemas resultantes de su anterior pertenencia al bloque económico del Este (COMECON), así como su integración en el ordenamiento comunitario.

f) Modificación, necesaria por los desequilibrios existentes entre las partes occidental y oriental, del sistema de financiación que la Ley Fundamental (en adelante LF) establece para la Federación (Estado central) y los demás entes territoriales (Estados Federados, Corporaciones locales, etc.).

g) Recepción, tanto del patrimonio como de las deudas de la RDA por la República Federal (con la cooperación del «Instituto Fiduciario Alemán» - Treuhandanstalt-). 
h) Reorientación del derecho social y de familia, así como de la legislación de los ámbitos cultural y científico (universitario) en los cinco nuevos Estados federados.

En la presente contribución no será posible abordar todos y cada uno de los problemas señalados. Nos limitaremos a examinar algunos de ellos de una especial importancia.

\section{BREVE RELACIÓN CRONOLÓGICA DEL DESARROLLO DE LOS ACONTECIMIENTOS}

El estudio de las principales etapas del proceso al que hacemos referencia, desde la revolución pacífica de los ciudadanos de la RDA, debe comenzar con la supresión del derecho, hasta entonces recogido en la propia Constitución, del SED (Partido Comunista de la DDR) a la dirección hegemónica del Estado, el pasado 1 de diciembre de 1989; a ello siguió la celebración de las primeras elecciones libres al Parlamento (Volkskammer) de la RDA el 18 de marzo de 1990 (la sesión constitutiva tuvo lugar el 5 de abril de 1990) y la formación del primer gobierno legitimado por las urnas (presidido por Lothar de Maizière) el 12 de abril del mismo año; celebración de las primeras elecciones municipales el 6 de mayo; la conclusión del primer tratado de Estado sobre la unión monetaria, económica y social entre las dos Alemanias, el 18 de mayo (entrada en vigor el 1 de julio), como paso previo para la unificación; la confirmación de la frontera polaco-alemana (línea Oder-Neisse) por los dos parlamentos alemanes (Bundestag y Volkskammer) el 21 de junio; la firma, el 2 de agosto, del Tratado para la celebración de elecciones conjuntas, en el que se estableció una fecha concreta, así como otras determinaciones referentes, por ejemplo, a los distritos electores o el número mínimo de votos necesario para la entrada en el Parlamento (respecto a ese último punto, el Tribunal Constitucional alemán corrigió, en virtud de la Sentencia de 29 de septiembre de 1990, el criterio entonces adoptado; la exigencia de un $5 \%$ de votos mínimos en todo el territorio alemán para la entrada en el Parlamento, fue reducida al establecerse que dicho tanto por ciento sería suficiente en cualquiera de las dos partes - occidental y oriental- de Alemania); la firma del "Tratado de la realización de la unidad estatal de Alemania" (TU) el 31 de agosto (aprobado por el Parlamento Federal el 20 de septiembre por 442 votos a favor, 47 en contra y 3 abstenciones ${ }^{3}$,

3 Los votos negativos corresponden a los diputados del partido verde ( $\mathrm{Die}$ Grünenn), así como a algunos diputados de la unión democrata-cristiana (CDU- 
así como por el Parlamento de la RDA, en la misma fecha, por 229 votos a favor, 80 en contra y una abstención ${ }^{4}$ ); la firma en Moscú del tratado para la plena restitución de la soberanía a Alemania, el 12 de septiembre, como resultado de las llamadas "Conversaciones dos más cuatro" (entre las cuatro potencias vencedoras de la Segunda Guerra Mundial, la RFA y la RDA) que puso fin a aquellos derechos que las potencias aliadas aún conservaban con respecto a Alemania y Berlín, y que ya fue considerado como válido en la fecha de la adhesión de la RDA a la RFA ${ }^{5}$; la declaración, por la que se puso fin a los derechos aún existentes de los comandantes aliados de Berlín sobre esta ciudad, del 2 de octubre; $y$, por último, la consumación de la unificación de Alemania a las 0 horas del 3 de octubre de $1990^{6}$.

Los Parlamentos de los nuevos Estados Federados, elegidos el 14 de octubre de 1990, se constituyeron el 3 de octubre. Por último, el pasado 3 de diciembre de 1990 se celebraron las primeras elecciones legislativas, desde la República de Weimar de la Alemania unida, cuyos resultados arrojaron una victoria de la coalición que hasta la fecha, desde 8 años atrás, y bajo la presidencia de Helmut Kohl, había dirigido los destinos de la República Federal.

\section{NATURALEZA JURÍDICA DEL TU}

La unificación de las dos Alemanias se ha realizado en virtud de lo preceptuado en el artículo 23 de la LF, que ofrece la posibilidad de que el

CSU). Estos últimos motivados por discrepancias personales en cuanto al tratamiento parlamentario ( $y$ en particular por motivos procedimentales) otorgado a la problemática de los antiguos territorios alemanes en Polonia y de la minoría germana, aún existente, en este último país. Cfr. "Archiv der Gegenwart", 1990-34923.

4 Los votos en contra corresponden al PDS (Partido Comunista reformado, sucesor del SED) y a la federación de los partidos "Bündnis 90-Grüne". Cfr. "Archiv der Gegenwart", 1990-34924.

5 Ver "Archiv der Gegenwart", 1990, 34870; FrowEIN, en "Deutschlands aktuelle Verfassungslage», Veröffentlichungen der Deutschen Staatsrechtslehrer (VVDStRL), 1990, págs. 7 y ss; Tomuschat, VVDStRL, 1990, págs. 70 y ss.; Rauschning, DVBI, 1990, págs. 393 y ss.; E. KLEIN, NJW 1990, págs. 1065 y ss.; HallbronNer, JZ, 1990, págs. 449 y ss.; BLumenWITz, NJW 1990; HoRN, NJW 1990, págs. 2173 y ss.; C. v. Goetze, NJW 1990, págs. 2161 y ss.

- Cronología de todo el proceso, en "Archiv der Gegenwart", 1990-34870, 34626/32, 34918/28/30, 34531. Ibidem, "Interims-Sachregister für das Jahr 1990", págs. 9 y 10. Ver, asimismo, los documentos en STERN/SCHMidT-BleibTREU, "Verträge und Rechtsakte zur Deutschen Einheit", vol. I, 1990, así como "Verträge zur Deutschen Einheit», vol. II, 1990. 
ámbito territorial de vigencia de la LF pueda extenderse también a "otras partes de Alemania". Ello puede explicarse por el hecho de que la LF debía limitarse, según las circunstancias imperantes en 1949 - año de su aprobación-, al territorio de los entonces Estados Federados?, aun cuando se consideraba como existente el Imperio Alemán, con sus fronteras de 1937.

Este punto ha sido abordado por la jurisprudencia del Tribunal Constitucional alemán, que, en su sentencia de 31 de julio de $1973^{8}$ sobre el tratado base (Grundvertrag) entre la RFA y la RDA del 21 de diciembre de 1972, había declarado: el Imperio no fue disuelto, sino que aún existe, incluso con capacidad jurídica, pero sin capacidad de obrar, debido a la carencia de órganos representativos institucionalizados de todo el anterior Estado en su conjunto. La RFA fue considerada como la persistencia de dicho Estado, excepto en cuanto a su extensión territorial. En relación con este último punto, habla el Tribunal sobre una «identidad parcial». Ello implica que tanto el territorio como el pueblo de la RFA no comprendía Alemania en su conjunto. Asimismo, la República Federal reconocía un pueblo y un territorio únicos como elementos del sujeto de Derecho Internacional Público Alemania (Deutsches Reich). El pueblo y territorio de la República Federal fueron considerados, por esta sentencia del Tribunal Constitucional, como una parte de aquéllos. A pesar de que la LF restringió - no podía ser de otra manera- la atribución del poder estatal a dicho ámbito territorial, que sólo comprendía los Estados Federados enumerados en el citado artículo 23 y en el Preámbulo de la Ley Fundamental, la República Federal se consideraba jurídicamente, en virtud del propio contenido de la LF, "responsable" (así lo expresa el Tribunal Constitucional alemán) también para toda Alemania. Con estas premisas ideológicas, parece lógico que el preámbulo de la LF, hasta el momento de la unificación, afirmara que los alemanes residentes en los mencionados Estados Federados se dotaran de una LF, actuando también en representación del resto del pueblo alemán. Por ese motivo, terminaba el Preámbulo con una llamada al conjunto del pueblo alemán a "completar" la unificación que, con este precepto de apertura hacia el resto del pueblo alemán, quedaba formalmente iniciada, mediante un acto que manifieste una autodeterminación libre en dicho sentido.

7 En lo concerniente a los Estados Federados actuales, la enumeración contenida en la LF se vio más tarde incrementada con la incorporación de Saarland y la modificada, en 1951, por la creación del Estado Baden-Württemberg.

${ }_{8}$ Amtl. Entscheidungssammlung (Repertorio oficial de Jurisprudencia del Tribunal Constitucional alemán), vol. 36, págs. 1 y ss. Cfr. FieDLER, «Europäische Integration und deutsche Frage" (Hacker/Mampel, editores), 1989, págs. 115 y ss. 
Así pues, el artículo 23 de la Ley Fundamental presentaba la posibilidad de adhesión de la otra parte del pueblo alemán, a través de un acto unilateral que aceptara la invitación formulada por la Ley Fundamental, con efecto vinculante para el pueblo alemán occidental y sus ins-

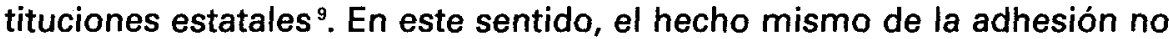
podía ser propiamente objeto de las negociaciones previas preparatorias del TU; jurídicamente, este último tan sólo se refería a las condiciones particulares de su realización.

Como ya hemos señalado, la incorporación de la RDA a la RFA se realizó el 3 de octubre de 1990. La declaración de adhesión supuso un acto de autodeterminación de la parte del pueblo alemán asentada en el territorio de la RDA, formulada por sus representantes elegidos en las urnas $^{10}$.

Como preveía el artículo 23, la Ley Fundamental debía extenderse a las nuevas partes del Estado alemán, y ello tendría que hacerse en virtud de un medio jurídico adecuado (en principio, sería suficiente una ley ordinaria), pues no podría realizarse automáticamente por sí mismo ".

El medio a que hacíamos referencia, junto a la ley aprobatoria del TU, emanada del Parlamento Federal, ha sido el artículo 3 del TU. El procedimiento de elaboración de dicha ley aprobatoria correspondía, excepcionalmente, a las exigencias de una reforma constitucional, que se formulan en el artículo 79 de la LF ${ }^{12}$. Ello se ha debido a que el Tratado, en su capítulo segundo, implicaba ciertas modificaciones de la propia LF, así como ciertas excepciones materiales de su vigencia durante un cierto período de tiempo en los nuevos Estados Federados, como se formula en el nuevo artículo 143 de la $\mathrm{LF}^{13}$.

Es interesante señalar que el propio artículo 23 de la Ley Fundamental ha sido considerado como superfluo, $y$, por tanto, eliminado tras la completa realización de la unidad alemana. Con esta eliminación se termina la hasta ahora viva discusión sobre el significado de la expresión "otras partes de Alemania» ${ }^{4}$.

9 Ver StARCK, JZ, 1990, págs. 349 y ss., y 352 y ss.; HäBerLe, JZ, 1990, págs. 358 y ss., y 358 y 359; BINNE, "Deutsch-Deutsche Rechts-Zeitschrift" (DtZ), 1990, págs. 209 y ss.; EPPING, JZ, 1990, págs. 805 y ss.

10 VON MüNCH, en «Kommentar zum Grundgesetz", 3. ed., 1985, Präambel, nota 17

MaUnz, en Maunz-Dürig, Kommentar zum Grundgesetz, art. 23, n. 43.

STERN, DtZ, 1990, págs. 289 y ss.

STERN, ibidem, págs. 290-291.

14 Cfr. Tomuschat, ibidem, pág. 78. 
Un camino diferente para la unificación, finalmente no utilizado, el supuesto por el artículo $146^{15}$, fue defendido por una parte minoritaria de la clase política e intelectual, y se refería a la creación de una nueva constitución aprobada libremente por el conjunto del pueblo alemán, que sustituyera a la propia Ley Fundamental. Esto hubiera implicado la introducción de nuevos conceptos, en parte de naturaleza diferente a los desarrollados por la jurisprudencia del Tribunal Constitucional alemán.

Debe señalarse que la creación de dicha nueva Constitución no habría supuesto necesariamente el nacimiento de un nuevo Estado, así como tampoco la aparición de un nuevo sujeto de derecho internacional público, a no ser que la voluntad expresa del pueblo así lo decidiera ${ }^{16}$.

A la mayor parte de las fuerzas representativas, la eficacia demostrada durante cuarenta años por la Ley Fundamental, desarrollada y profundizada por el Tribunal Constitucional, junto a la posibilidad de una rápida y adecuada disponibilidad, les pareció motivo suficiente para elegir el artículo 23 como el apropiado para realizar la unificación.

El artículo 4 del TU modifica el texto del artículo 146 de la Ley de Leyes alemana, en cuanto que establece, el mencionado artículo 4 TU, que la Ley Fundamental es válida para todo el pueblo alemán desde la conclusión de la unificación en libertad de Alemania, y que podrá ser sustituida por una nueva Constitución, si bien esto no resulta necesario. A través de este precepto, se aclara que la utilización del artículo 23 de la LF no es incompatible con una aplicación posterior del artículo 146. Esto pone fin a la controversia dogmática al respecto.

La discusión anterior sobre la relación entre los dos preceptos constitucionales ha tenido como resultado la actual redacción del artículo 5 del TU, que contiene varias recomendaciones respecto a posibles modificaciones constitucionales; en particular, el Parlamento alemán deberá, en el período de dos años, reflexionar sobre una perfección del propio sistema federal, la adopción de disposiciones adicionales que conciernan a los fines básicos del Estado (Staatsstrukturziele), en particular aquéllas en relación con la protección del medio ambiente o el derecho al trabajo (hasta ahora sólo recogido en la antigua Constitución de la RDA, pero no en la $L F$, ya que esta última tanto sólo contenía normas di-

15 Ver ISEenSE, ibidem, págs. 48 y ss; págs. 54-55; THIEME, DÖV, 1990, págs. 401 y ss.; Frowein, ibidem, págs. 14 y ss.; TOMUSCHAT, ibidem, págs. 88 y ss.; STARCK, ibidem, págs. 354-355; HäBERLE, ibidem, pág. 359. Respecto al texto modificado del artículo 146 LF, ver STERN, DtZ, ibidem, págs. 293-294.

16 ISENSEE, VVDStRL, ibidem, págs. 39 y ss., pág. 46. 
rectamente aplicables, entre las cuales no se encuentra el derecho al trabajo). También recomienda, el art. 5 del TU, volver a reflexionar sobre la posibilidad y conveniencia de la elaboración de una nueva Constitución, a través del procedimiento previsto en el art. 146 de la LF (esto haría necesaria la celebración de un referéndum para la definitiva aprobación del nuevo Texto Fundamental).

Es importante destacar, asimismo, el contenido del nuevo artículo 143 de la LF, redactado sobre la base del art. 4.5 del TU, que permite que el derecho vigente en el territorio de los nuevos Estados Federados, durante un período transitorio, que se prolongará, en principio, hasta el 31 de diciembre de 1992, no sea necesariamente compatible con la Ley Fundamental, bajo la condición de que su adaptación al ordenamiento constitucional no sea posible por la problemática específica que afecta a estos territorios. Tales dispensas no podrán colisionar con la garantía del contenido esencial de los derechos fundamentales, tal y como se recoge en el artículo 19, párrafo 2.․, LF. No podrán, asimismo, rebasar los límites impuestos en el artículo 79.3 LF, el cual establece una protección contra la reforma constitucional del principio de la dignidad humana (art. 1.1 LF) y de aquellos que derivan del art. 20 LF (Estado de derecho, Estado social, Estado federal, república), así como la garantía de la propia existencia de Estados Federales y del derecho de participación de éstos en la función legislativa federal.

Estos límites a las dispensas constitucionales derivan de la propia naturaleza del sistema constitucional, ya que éstas no son sino modificaciones atípicas (en cuanto a su contenido, duración y extensión geográfica) del propio texto constitucional que recortan su virtualidad habitual y, en consecuencia, reciben el tratamiento de una reforma constitucional.

\section{RÉGIMEN ESPECIAL DEL DERECHO DE PROPIEDAD}

Básicamente, las cuestiones relativas al derecho de propiedad que derivan de la partición de Alemania, de la emigración masiva de ciudadanos de la RDA a la RFA y de la diversidad de los ordenamientos jurídicos de ambos Estados, se encuentran recogidas en la denominada «Declaración común de los gobiernos de la RFA y la RDA sobre la regulación de los problemas patrimoniales aún no resueltos" del 15 de junio 1990 (Anexo III del TU).

El mismo artículo 143 LF aporta una disposición importante, en su párrafo 3., sobre el tratamiento jurídico que habrá de aplicarse a los ca- 
sos de expropiación y otras acciones contra el derecho de propiedad en la antigua RDA. Este artículo se refiere al artículo 41 del TU, que declara que el Anexo III es parte integrante del mismo.

Como principio general, se reconoce el derecho de los antiguos propietarios a ejercer la acción de reversión sobre aquellos bienes expropiados. El régimen jurídico concreto de esta problemática se encuentra establecido, desde el momento de la unificación, en la "Ley para la regulación de las cuestiones patrimoniales no resueltas", y que forma parte del Anexo II del TU.

Resulta interesante, desde la perspectiva de la ciencia del derecho constitucional, que la LF declare, en su artículo 143, la compatibilidad entre el derecho fundamental a la propiedad $y$ aquellas disposiciones del mencionado Anexo III al TU que confirman ciertas expropiaciones (en particular las efectuadas entre los años 1945 y 1949 por las fuerzas de ocupación $\left.{ }^{17}\right)$. Esta disposición, contenida en el mencionado nuevo artículo de la LF, es motivo de una actual discusión doctrinal en Alemania. No se puede excluir una posible colisión con la propia garantía del contenido esencial del derecho fundamental a la propiedad (artículo $14 \mathrm{LF}$ ) y con el principio del Estado de derecho (artículo $20 \mathrm{LF}$ ). Del artículo 14 de la Ley Fundamental, exige la obligación del Estado de restitución de la propiedad.

\section{LA CREACIÓN DE NUEVOS ESTADOS FEDERADOS}

EI TU prevé, en un lugar destacado (artículo 1), el establecimiento de los siguientes "Länder»: Mecklenburg-Vorpommern, Brandenburg, Sachsen-Anhalt, Sachsen y Thüringen. Desde el mismo momento de su constitución forman parte de la RFA como Estados Federados, según el procedimiento trazado por el artículo 23 de la LF.

En lo que a Berlín concierne, cuya parte occidental tenía el status constitucional de Estado Federado (pero cuyas facultades, en comparación con las de los demás Estados Federados, se encontraban limitadas

17 Ver también el artículo 41.2 TU, donde también se recogen otras circunstancias (cuando solares y edificios que fueron expropiados sean necesarios para la realización urgente de proyectos de interés público) por las que ciertas expropiaciones serán, asimismo, confirmadas. Ver STERN, DtZ 1990, págs. 289 y ss., 291-292; IsENSEe, ibidem, págs. 60 y ss.; KITTKE, DtZ 1990, págs. 179 y ss., 181. 
en virtud de los derechos que los aliados aún conservaban sobre la ciudad), ha adquirido, junto a la condición de capital de la República (como se establece en el artículo 2.1 del TU), el pleno status de un Estado Federado, como se indica en el nuevo texto del Preámbulo de la LF.

La antigua RDA nunca llegó a articular un auténtico sistema federal: los elementos federales contenidos en la Constitución de 1949 fueron esencialmente eliminados por la abolición en 1952 de los gobiernos y parlamentos de los Estados Federados inicialmente existentes, así como por la supresión en 1958 de la Cámara de representación (que tan sólo contaba con el derecho de veto suspensivo) de dichos Estados ${ }^{18}$. La Constitución de 1968, modificada en 1974, no reconoció la existencia de Estados Federados ${ }^{19}$.

En cuanto al estatuto jurídico de estos nuevos Estados Federados, no se diferencia del de los anteriormente existentes. De ello se desprenden algunas consecuencias relevantes:

1. Son considerados como auténticos Estados, con los tres elementos básicos: territorio, población y organización política (esta última, compartida con la Federación, y de hecho con una supremacía de ésta, sobre todo en el ámbito legislativo);

2. La existencia de dos poderes constituyentes, con respecto a cada Estado (central y federado), que podrán, indistintamente y para su propio espacio constitucional («Verfassungsraum») crear, y posteriormente modificar, una Constitución, así como establecer los respectivos órganos de justicia constitucional (si bien la Federación ya está dotada de su propia Ley Fundamental, todos los Estados Federados de reciente creación deberán afrontar la elaboración de sus propias constituciones $y$, con ellas, establecer la correspondiente jurisdicción constitucional ${ }^{20}$. Los "espacios constitucionales" que pertenecen a los Estados Federados deberán supeditarse a las estructuras fundamentales del Estado central ( $\mathrm{Fe}$ deración); dicha exigencia resulta de la llamada "cláusula de homogeneidad" que establece el artículo 28.1 de la LF (dicha homogeneidad implica el respeto a los principios que proclama el artículo 20: República, Democracia, Estado de derecho y Estado social).

18 Maunz/Zippelius, Deutsches Staatsrechts, 27.. ed., 1988, págs. 422-423.

19 Ver GBI DDR, parte I, 1974, 432; MAUnZ/ZIPPELIUS, ibidem, pág. 418.

${ }^{20}$ Cfr. ARnold, "La ripartizione delle potestà fra Bund e Länder alla luce della giurisprudenza della Corte Constituzionale tedesca», en "Le Regioni", 1988, págs. 865 y ss. Ver también, con respecto a la unificación alemana, WUERMELING, "Auf dem Weg zur Einheit: Die Rolle der deutschen Bundesländern, NJW, 1990, págs. 1079 y ss. 
3. El carácter estatal de los Estados Federados, aun de los nuevos, implica también el principio básico de "presunción de competencia» (para ejercer las funciones estatales: ejecutiva, legislativa y judicial). Este principio es necesariamente limitado. Dicha limitación es especialmente patente en el ámbito legislativo: a la Federación le corresponde un número importante de diferentes tipos de competencias legislativas, entre las cuales la llamada "competencia concurrente" ${ }^{21}$ es la más amplia e incisiva y que ha sido profusamente utilizada. En el artículo 31 de la LF se establece un importante instrumento para resolver posibles conflictos de normas entre la Federación y los Estados Federados. El criterio general en él establecido resulta claramente favorable para la Federación. Esta estructura afecta a los nuevos Estados Federados, si bien con las particularidades que se establecen en el TU (en líneas posteriores nos ocuparemos de esta última cuestión). En lo que a la ejecución de leyes, aun las federales, concierne, son competentes los Estados Federados (existen, en cuanto a las leyes federales, ciertas excepciones ${ }^{22}$ ).

4. Los Estados Federados, también los nuevos, participan en la función legislativa federal por medio del Ilamado "Consejo Federal" (Bundesrat). En el contexto de la unificación, el artículo 51.2 LF, que establecía la proporción de votos en el "Bundesrat" correspondientes a los Estados Federados, fue modificado estableciéndose el criterio por el cual se atribuyen tres votos, como mínimo, a cada Estado Federado; cuatro votos para los que tengan más de dos millones de habitantes; cinco para aquellos de más de seis millones y seis votos para los de más de siete millones de habitantes. Nos parece ésta una diferenciación más adecuada para la representación de los Estados Federados en el "Bundesrat".

La mencionada Ley de la RDA del 22 de julio de 1990, "Ländereinführungsgesetz", en vigor desde el 3 de octubre, ha reformado la existencia y la propia estructura de los nuevos Estados Federados, ya bajo la base, esencialmente, de la concepción de la RFA. Es claro que el régimen actual de los Estados Federados se orienta según los principios básicos contenidos en la LF.

Un elemento esencial de las relaciones entre el Estado central y los federados es el sistema de atribución financiera, que se regula en los artículos 105 y ss. de la LF. EI TU contiene en su artículo 7 una serie de importantes regulaciones $y$ disposiciones especiales, en particular con

21 Con respecto a esta "competencia concurrente», ver los artículos 72 y 74 de la Ley Fundamental.

${ }^{22}$ Ver artículos 85 y ss. de la Ley Fundamental. 
respecto al artículo $106 \mathrm{LF}$, que representa la base de la llamada "compensación financiera vertical» entre la Federación, los Estados Federados y las Corporaciones Locales.

EI TU prevé, asimismo, modificaciones durante un cierto período de tiempo en el ámbito de los llamados «impuestos comunes" ${ }^{23}$ (Gemeinschaftsteuern), cuyo ingreso corresponde tanto a la Federación como a los Estados Federados (también parcialmente a las Corporaciones Locales), especialmente en lo concerniente al Impuesto sobre el Valor Añadido (Umsatzsteur), el Impuesto sobre la Renta (Einkommensteur) y a la concesión de subsidios del «Fondo para la Unidad Alemana» (Fonds "Deutsche Einheit"); con respecto a este último, el $85 \%$ de sus fondos se dedican, desde el 3 de octubre, a la subvención particular de los nuevos Estados Federados, y el 15\% restante a tareas centrales en estos nuevos territorios ${ }^{24}$.

\section{RECEPCIÓN DEL DERECHO FEDERAL EN LOS NUEVOS ESTADOS FEDERALES}

La recepción del derecho federal en los nuevos Estados Federales, asi como la confirmación de ciertas normas de la antigua RDA, es uno de los puntos fundamentales del TU ${ }^{25}$.

El principio general consiste en la incorporación de los nuevos Estados Federados, en el mismo momento de la adhesión de la RDA a la RFA, al ordenamiento jurídico de esta última (articulo 8 del TU). Las excepciones a este principio general las recoge el TU en el extensísimo Anexo I, que se encuentra subdividido en 19 capítulos que se orientan, en particular, a los campos materiales de los respectivos departamentos ministeriales y cuyo apartado 1 enumera aquellas normas jurídicas o tratados internacionales que no deberán extenderse a los nuevos Estados Federados (el número tanto de unas como de los otros es ciertamente reducido); en el apartado 2 del mismo se indican aquellas normas jurídicas de la RFA que se han modificado, completado o suprimido

23 Ver al respecto los artículos 106, 3, 7 .

24 Para ulteriores detalles respecto a la problemática financiera de la unificación alemana, ver "Memorándum del TU» (Denkschfrifft zum Einigungsvertrag), notas al artículo 7.

${ }^{25}$ Ver WASMUTH, DtZ 1990, págs. 294 y ss., 295 y ss. 
por razón de la adhesión; finalmente, el apartado 3 contiene aquellas disposiciones que deberán entrar en vigor, bajo determinadas condiciones de adaptación. Un ejemplo para el último caso es la ley de la RFA que concierne a la organización del poder judicial (Gerichtsverfassungsgesetz), ley que contempla la persistencia del hasta entonces sistema existente en la RDA con tribunales para pequeños ámbitos territoriales (Kreisgerichte) y para otros algo más extensos (Bezirksgerichte), tanto a la creación de las condiciones materiales y personales que sean necesarias para la introducción del sistema occidental ${ }^{26}$. Esto significa que las competencias de la jurisdicción civil, penal, y, lo que supone una clara particularidad, también contencioso-administrativa ${ }^{27}$, fiscal, laboral y social, están atribuidas a estos mencionados tribunales de la RDA.

Todos los nuevos Estados Federados han adoptado, en gran medida, el derecho de la RFA, cuyo ordenamiento correspondía, también en el pasado, a los fines del Estado de derecho y social, fines asimismo perseguidos en el marco de la revolución pacífica en la Alemania del Este ${ }^{28}$.

La consecuencia, como principio general, de la recepción del derecho federal de la RFA es que el derecho anteriormente emanado de la RDA será abolido ${ }^{29}$.

Aún permanecen, sin embargo, en vigor aquellas disposiciones del derecho de la RDA que corresponden, según la distribución de competencias en la LF, a los Estados Federados, bajo la condición de que sean compatibles con el propio texto constitucional (consecuencia lógica del principio de jerarquía normativa). Así ocurre, por ejemplo, en lo relativo a la ley de la RDA sobre la responsabilidad del Estado (Staatshaftungsgesetz) de 1969, aun cuando haya sido esencialmente modificada ${ }^{30}$.

Aquellas normas de la RDA que regulan materias de carácter federal, según lo prescrito al respecto en la LF, y que no se encuentren aún reguladas por el propio derecho de la RFA, continuarán teniendo vigen-

26 Ver Brachmann, DtZ 1990, págs. 298 y ss.

27 Ver Ley de la RDA del 26 de junio de 1990 (GBI. I n. 41); SendLER, DtZ 1990, págs. 166 y ss.; BERNET, DOV 1990, págs. 409 y ss.

${ }_{28}$ Memorándum..., ibidem, notas al artículo 9. Ver también ENGELHARD, DtZ 1990, págs. 129 y ss.; WASMUTH, ibidem, págs. 296 y ss.

${ }_{29}$ Memorándum..., ibidem.

30 Ver GBI. I 34. 
cia como derecho del ámbito de los Estados Federados, hasta que la Federación elabore una legislación al respecto. Para ello, dichas normas deberán ser compatibles con la LF ${ }^{31}$.

Las normas jurídicas de la RDA que, según los criterios materiales establecidos por la LF, sean del ámbito de los Estados Federados y violen la LF, perderán su vigencia. Esta norma general será motivo de excepción cuando las materias que regulen se encuentren entre las recogidas en el artículo 143 de la LF (según lo previsto en el artículo 4.5 del TU), asi como en el Anexo II.

En el caso de aquellas normas de la RDA enumeradas en el Anexo Il que pertenezcan al ámbito de las "competencias-exclusivas" de la Federación, a las "competencias-concurrentes" o a las denominadas "competencias-marco", continúan siendo vigentes, pasando a ser derecho federal parcial en los nuevos Estados Federados, mientras que en el resto del territorio de la RFA serán válidas las normas hasta entonces vigentes en dicho territorio ${ }^{32}$.

Importantes ejemplos del derecho de la antigua RDA que aún continúa vigente, en virtud del TU (artículo 9.3 en conexión con el Anexo II), son aquellas leyes emanadas tras la celebración de las primeras elecciones libres en dicho país, como la Ley sobre la Autonomía Comunal (es decir, referente a los municipios - Gemeinden- $y$ a las asociaciones municipales - Landkreise-l del 17 de mayo de $1990^{33}$, excepto en lo referente al derecho de voto de los extranjeros.

La normas que pertenecian al ordenamiento jurídico de la RDA, con anterioridad a la señalada fecha de la celebración de elecciones libres, han sido, en su amplia mayoría, abolidas o sustancialmente modificadas, aún ya en el período transitorio entre dicha celebración y la adhesión a la RFA. El Código de legislación laboral (Arbeitsgesetzbuch) y el Código Penal (Strafgesetzbuch), por ejemplo, fueron esencialmente modificados.

El Anexo II del TU recoge los textos de una serie de nuevas leyes que entraron en vigor junto con el propio Tratado; así, por ejemplo, la mencionada Ley sobre las "cuestiones patrimoniales no resueltas" (regelung offener Vermogensfragen) o la ley sobre el «impuesto para las Iglesias" (Kirchensteuer).

31 Ver artículo 9.1 del TU.

${ }^{32}$ Ver artículo 9.4 del TU; asimismo, artículo $9.3 \mathrm{y}$, para posteriores detalles, Memorándum, ibidem.

33 GBI. I, n. 28, pág. 255. 


\section{OTRAS CONSECUENCIAS JURÍDICAS DE LA UNIFICACIÓN ALEMANA}

Debido a la necesaria limitación de espacio, no nos será posible sino mencionar algunos otros puntos con importantes consecuencias jurídicas, íntimamente conectados con la unificación. La organización administrativa y judicial, incluyendo también las Universidades y demás instituciones del mundo de la cultura, la ciencia y el deporte, así como las emisoras públicas de radio y televisión en la RDA, han sido, como está previsto en el artículo 13 del TU ${ }^{34}$, transferidas al ámbito de los Estados Federados, a los que la LF atribuye precisamente dichas competencias.

El estatuto del funcionario deberá ser adaptado, en términos generales (también se recogen algunas excepciones al respecto), en los nuevos Estados Federados, al principio consagrado en el artículo 33 de la $\mathrm{LF}^{35}$.

En el capítulo VI del TU se aborda la problemática específica de la transición del patrimonio de la RDA a la Federación, así como a los nuevos Estados Federados y a las Corporaciones Locales y otros entes públicos (ver artículo 21 TU), con la participación, en la adjudicación de dicho patrimonio, del "Instituto Fiduciario Alemán" ${ }^{36}$.

El principio de seguridad jurídica exige que los actos de la administración y del poder judicial conserven vigencia, excepto cuando éstos sean impugnados $y$, en su caso, legalmente abolidos ${ }^{37}$.

Otros campos esenciales regulados en el TU son disposiciones orientativas sobre el derecho laboral y social (artículo 30), derecho de familia y protección de la mujer (artículo 31), la sanidad pública (artículo 33), la protección del medio ambiente (artículo 34) —campo muy deficitario en la RDA-.

El último capítulo con disposiciones materiales, el VIII, es el concerniente a la cultura, que se califica como una de las bases de la conti-

${ }^{34}$ Al respecto, existen otras disposiciones en los artículos 14,15 y 16 del TU.

35 Ver Memorándum, ibidem, notas al artículo 20.

${ }^{36}$ Ver artículos 22 y 25 TU. Con respecto a la recepción de las deudas estatales de la RDA, consultar el artículo 23 TU. Con respecto a ciertos patrimonios especiales (red ferroviaria, correos), artículos 26 y 27 TU.

37 Ver, al respecto, los artículos 18 y 19 del TU; también los fundamentos para la rehabilitación de los presos y perseguidos políticos, en el artículo 17 TU. 
nuidad de la nación alemana, también en los años de separación (artículo 35); a la radio y televisión, que ahora deberán ser independientes del Estado y pluralistas (artículo 36), y la educación, la ciencia y la investigación (artículos 37 y 38) y, finalmente, el deporte (artículo 39), que deberán tener un régimen y administración autónomo e independiente.

Esta contribución se ha limitado a abordar algunas cuestiones de relevancia interna. No son objeto del presente trabajo los múltiples $y$ complicados problemas que la unificación de Alemania implica en el ámbito del Derecho internacional público - lo que concierne a la reflexión dogmática del destino jurídico de los tratados internacionales concluidos por la antigua RDA, materia abordada en el artículo 12 TU de forma pragmática, bajo el principio de "protección de confianza" - ${ }^{38}$, así como en el ámbito del Derecho comunitario.

El artículo 10 TU prevé la plena realización del Derecho comunitario en el territorio de los nuevos Estados Federados, consecuencia jurídica de la pertenencia de estos Estados a la RFA, país miembro de las Comunidades Europeas, según el artículo 227 del Tratado de la CEE ${ }^{39}$.

El propio contenido del TU no se ha terminado de aplicar aún. Por este motivo, una abundante problemática está aún por venir. Probablemente tanto el Tribunal Constitucional como el Tribunal Supremo Administrativo (Bundesverwaltungsgericht) alemán tendrán que ocuparse con cuestiones derivadas de la aplicación del TU, y ello estará especialmente motivado por la posibilidad, que el propio TU establece (artículo 44), de que cualquiera de los nuevos Estados Federados podrán acudir a los tribunales para reclamar tanto sus derechos como los de la desaparecida RDA (los que estén reconocidos en el TU).

En cualquier caso, pensamos que la realización de un instrumento jurídico de esta naturaleza en el breve período de tiempo en que se ha conseguido, supone un loable esfuerzo de los responsables de su realización. Pero ante todo, el TU no supone sino la expresión jurídica del legítimo deseo del pueblo alemán de volver a estar unido.

38 Tomuschat, ibidem, págs. 81-82.

39 Randelzhofer, WDStRL, ibidem, págs. 101 y ss.; Grabitz/v. Bogdandy, NJW, 1990, págs. 1073 y ss.; $v$. BogdANDY, en Rivista di Diritto Internazionale, 1990, págs. 47 y ss.; Rauschning-HaCH, EuZW, 1990, págs. 344 y ss.; H.-J. WolfF, NJW, 1990, págs. 2168 y ss. 